\title{
A Microeconomic Foundation for Optimum Currency Areas: The Case for Perfect Capital Mobility and Immobile Labor Forces
}

\author{
Masayuki Otaki \\ Institute of Social Science, University of Tokyo, Tokyo, Japan \\ Email: ohtaki@iss.u-tokyo.ac.jp
}

Received June 6, 2012; revised July 2, 2012; accepted August 1, 2012

\begin{abstract}
This article provides a microeconomic foundation for Mundell's optimum currency area theory. We consider twin countries where labor forces are fixed to each country although the real capital moves internationally. When the central bank in each country behaves non-cooperatively, it will raise the domestic interest rate to attract more real capital and increase the rent of her residences. However, the fierce competition between the central banks ultimately exacerbates the disparity in income distribution. Moreover, when the real capital or the financial intermediary as its agent does not have a nationality, the worsened income distribution also results in the inefficient resource allocation. Thus, such twin countries should unify their central banks and coordinate their monetary and interest policies. In other words, these countries constitute an optimum currency area.
\end{abstract}

Keywords: Optimum Currency Area; Capital without a Nationality; Non-Cooperative Game between Central Banks; Disparity in income Distribution; Inefficiency of Resource Allocation

\section{Introduction}

Income disparity is not limited to developing countries. Advanced economies also face this growing problem. This article considers why such an undesirable economic consequence is invoked when constructing a microeconomic foundation for the optimum currency area theory originating from Mundell's [1] seminal work.

As Mundell [1] emphasizes, the mobility of production resources plays a crucial role when we consider which economies should constitute an optimum currency area. We deal with the case in which both labor forces are immobile and have a nationality but real capital with no nationality can move internationally at the owners' or their agents' (banks, security companies and etc. ) discretion. Such a setting is plausible when we observe that foreign direct investment is generally preferable to certifying work visas.

When small twin countries with identical economic structure are in this situation, their central banks compete to invite more real capitals to enrich their economy as long as the countries attain full employment. Nonetheless, such competition has the following devastating conesquence.

If one central bank pursues a high-interest policy to attract more real capital, the other central bank counterof- fers with a higher interest rate. Such a cumulative process does not cease until a surplus from working that is the benefits of the high interest policy vanish entirely.

Consequently, the non-cooperative behavior of two central banks brings about a serious income disparity between capital and labor. Furthermore, since capitals or financial intermediaries as their agents are assumed to have no nationality, the emerging disparity also results in the large welfare losses for these two nations.

The unification of two central banks is desirable for overcoming such a difficulty. The small twin countries should be at least economically integrated. Then, the same amount of money is supplied to ensure full employment and the interest rates offered to non-nationality real capitals become identical at the lowest level.

Accordingly, each country is supplied with an amount of real capital, and thus, the income disparity and inefficient resource allocation within the nations are entirely resolved. That is, the small twin countries constitute an optimum currency area whenever the real capital mobility is complete.

The remainder of this paper is structured as follows. In Section 2, we construct a small twin country model based on Otaki [2]. In Section 3, we compare the non-cooperative and cooperative monetary policies, and prove the inevitability of optimum currency areas. In Section 4, we 
summarize the analyses and results. In Section 5, we provide brief concluding remarks.

\section{The Model}

\subsection{Structure of the Model}

We use a two-period overlapping generation model in a production economy with money. The world consists of twin countries $\mathrm{A}$ and $\mathrm{B}$, whose economic structures are identical, and the rest of the world. Each country has residents who cannot move elsewhere and who live in two periods with the density $[0,1]$.

Each resident specializes in producing one differentiated goods with the help of real capitals when he/she is young. Real capital, whose owners have no nationality, exists with the density $[0,1] \times[0,2]$. Hence, each resident can potentially deploy the real capitals with the density $[0,1]$. Capital income is also earned when the owner is young, and then capital itself is passed to a descendant. Once an owner determines the location of his/her capital, he/she lives in that country even after his retirement. The minimum rate of return from the rest of the world $(\tilde{r})$ is guaranteed to all capital owners. Furthermore, for simplicity, a unit real capital combined with a resident's business skills produces a unit good.

The income distribution between residents and capital owners is determined by a negotiation. The negotiation process, which was developed by Otaki [2], is assumed to be the following two-stage game. First, a resident determines how much capital to deploy in order to maximize his/her income from business skills. Second, given the volume of capital deployed and goods produced, the residents and owners mutually determine the income distribution in accordance with the asymmetric Nash bargaining solution.

In addition, there is a central bank in each country, which pursues the social welfare of her residents. Each central bank's policy variables are the nominal money supply and the real interest rate (i.e., the rate of return for capital). We assume that a central bank manipulates the real interest rate by intervening in the negotiation process between her residents and the non-nationality capital owners or financial intermediaries that are agents of capital owners. That is, a central bank can control the bargaining power of her residents through moral suasion.

\subsection{Construction of the Model}

\subsubsection{Individual's Utility and Consumption Functions}

We assume that all individuals (including capital owners) have the same concave and linear homogenous lifetime function:

$$
U \equiv u\left(c_{1}, c_{2}\right), c_{i} \equiv\left[\int_{0}^{1}\left[c_{i}(z)\right]^{1-\eta} \mathrm{d} z\right]^{\frac{1}{1-\eta}},
$$

where $c_{i}(z)$ is the consumption of $\operatorname{good} z$ during the $i$ th stage of life. We can derive the following corresponding indirect utility function $I U$ :

$$
I U \equiv \frac{Y_{t}}{\varphi\left(p_{t}, p_{t+1}\right)}=\frac{y_{t}}{\varphi(1, \rho)}, y_{t} \equiv \frac{Y_{t}}{p_{t}}, \rho \equiv \frac{p_{t+1}}{p_{t}},
$$

where $Y_{t}$ is the nominal income and $p_{t}$ is the price index defined by

$$
p_{t} \equiv\left[\int_{0}^{1}\left[p_{t}(z)\right]^{1-\eta} \mathrm{d} z\right]^{\frac{1}{1-\eta}}
$$

Furthermore, the consumption function of the younger generation $C$ is

$$
C \equiv c(\rho) y_{t}
$$

Finally, the demand function for $\operatorname{good} z$ is

$$
D(z) \equiv\left[\frac{p(z)}{p}\right]^{-\eta} y^{d},
$$

where $y^{d}$ is the aggregate demand.

\subsubsection{Production Process by the Two-Stage Game}

To develop the aforementioned production process, we consider the following two-stage game.

1) Each resident maximizes his/her income from business skills by deploying non-nationality capitals;

2) The resident and capital owners or financial intermediaries negotiate their income distribution in accordance with the asymmetric Nash bargaining solution the threaten point of which is $\left[0, r^{*}\right]$.

We must solve this problem by backward induction. In the second stage game, the corresponding generalized Nash product $G(z, i)$ is

$$
G P(z, i) \equiv\left[p(z)-r^{i}\right]^{\theta-\varepsilon_{i}}\left[r^{i}-r^{*}\right]^{1-\theta+\varepsilon_{i}},
$$

where $\theta$ is the degree of tolerance, that is, residents' discount rate applied to the negotiation process with capital owners or their agents ${ }^{1} . \theta-\varepsilon^{i}$ is the modified (actual) discount rate; that is, $\varepsilon^{i}$ denotes the power of moral suasion of $i$ country's central bank to decrease the residents' discount rate to induce more capital rapidly into the domestic economy. $r^{i}$ is the domestic rate of return for a unit capital.

The shape of the product is derived from two properties of the model. First, the objective function is linear on the real income as indicated by (1). Second, the production (or demand) volume is already determined by the first stage of the game.

Maximizing (4) with respect to $r^{i}$, we obtain the equilibrium domestic rate of return $r^{i^{*}}$ :

$$
r^{i^{*}}=\left[1-\theta+\varepsilon^{i}\right] p(z)+\left[\theta-\varepsilon^{i}\right] \tilde{r} .
$$

${ }^{1}$ See Rubinstein [3] for a detail interpretation concerning the asymmetric Nash bargaining solution. 
Taking (5) into consideration, the maximization problem of the first stage can be expressed as

$$
\begin{aligned}
\pi^{i}(z) & \equiv \max _{p(z)}\left[p(z)-r^{i^{*}}\right] D(z) \\
& =\left[\theta-\varepsilon^{i}\right] \max _{p(z)}[p(z)-\tilde{r}] D(z)
\end{aligned}
$$

The solution to (6) is

$$
p^{*}(z)=\frac{\tilde{r}}{1-\eta^{-1}}, \forall z .
$$

Hence, the price level $p$ is constant over time and the equilibrium inflation rate is $\rho^{*}=1$. Substituting (3) and (7) into (6), we obtain

$$
\frac{\pi^{i}(z)}{p^{*}}=\left[\theta-\varepsilon^{i}\right] \eta^{-1} y^{d i}
$$

where $y^{d i}$ denotes the real GDP of country i. From (1), it is clear that (8) corresponds to the social welfare of residents in country $i$.

\subsubsection{The Market Equilibrium}

In both countries, money is supplied through the unexpected transfer to the older generation; thus, taking (2) into consideration, the equilibrium condition for the domestic aggregate goods market becomes

$$
y^{d i}=c(1) y^{d i}+m^{i} \Rightarrow y^{d i}=\frac{m^{i}}{1-c(1)},
$$

where $m^{i}$ denotes the real money supply within country $i$. The second term of (9) corresponds to the aggregate expenditure of the older generation.

Owing to the perfect mobility, the real capital market achieves equilibrium when

$$
k^{i}= \begin{cases}2, & \text { if } \varepsilon^{i}>\varepsilon^{j} \\ 1, & \text { if } \varepsilon^{i}=\varepsilon^{j} \\ 0, & \text { if } \varepsilon^{i}<\varepsilon^{j}\end{cases}
$$

where $k^{i}$ is the amount of capital that has been invested in country $i$.

The model contains five types of endogenous variable $\left(r^{i^{*}}, p^{*}, \pi^{i}, y^{d i}, k^{i}\right)$, two types of exogenous variable $\left(\varepsilon^{i}, m^{i}\right)$, and five structural Equations (5) and (7)-(10). Thus, the model is closed.

\subsection{The Non-Cooperative Game between Central Banks and the Disparity in Income Distribution}

Because of the international mobility of real capitals and the representation of social welfare (8), each central bank is eager to attract more capital and enrich its country. Such competition is described by the following two-stage game. In the first stage, central banks determine $\left(\varepsilon^{A}, \varepsilon^{B}\right)$. Next, they decide how much money they supply (i.e.,
$\left.\left(m^{A}, m^{B}\right)\right)$.

To solve the equilibrium of this game, we must begin with the second stage. Since the outcomes of the first stage are summarized by (10), taking the social welfare (8) and the equilibrium condition for each aggregated goods market (9) into consideration, the best response of each central bank is to maintain the full-employment equilibrium, which is defined as the amount of real capital that is associated with its country. Hence, the following dominant strategy in this game corresponds to the result of the first-stage game. That is,

$$
m^{i}= \begin{cases}2, & \text { if } \varepsilon^{i}>\varepsilon^{j} \\ 1, & \text { if } \varepsilon^{i}=\varepsilon^{j} \\ 0, & \text { if } \varepsilon^{i}<\varepsilon^{j}\end{cases}
$$

Since full-employment is assured in the second stage, central banks strive to invite as much real capital as possible. The following theorem holds concerning the uniqueness of the Nash equilibrium:

Theorem 1.

The unique Nash equilibrium is characterized by

$$
\left(m^{i^{*}}, \varepsilon^{i^{*}}, \frac{\pi^{i^{*}}}{p^{*}}\right)=(1, \theta, 0)
$$

\section{Proof.}

$<$ Sufficiency $>$ If (12) is satisfied, there is no active incentive to diverge the strategies because no additional gain is obtained by lesser $\left(m^{i^{*}}, \varepsilon^{i^{*}}\right)$. Hence, (12) is a

Nash equilibrium.
$\quad<$ Necessity $>$ Suppose that $\frac{\pi^{i^{*}}}{p^{*}}$ is strictly positive in
some Nash equilibrium. Then,

$$
\frac{\pi^{i^{*}}}{p^{*}} \geq \frac{\pi^{j^{*}}}{p^{*}} \Leftrightarrow \varepsilon^{i^{*}} \geq \varepsilon^{j^{*}} .
$$

By selecting a $\varepsilon^{j^{* *}}$ slightly larger than $\varepsilon^{i *}$, country $j$ improves her social welfare as much as

$$
\left[\theta-\varepsilon^{j^{* *}}\right] \eta^{-1}>0
$$

Thus, there is an incentive to diverge from the equilibrium. This is a contradiction.

The economic implication of Theorem 1 is quite serious. As long as two central banks extend the non-cooperative game to attract more capital, the income disparity deepens against their intentions. Owing to the competition, residents' earnings from business skills are utterly absorbed by the capital income. Since, as seen in (8), the social welfare of residents is proportional to their income, the deepening income disparity also results in a less efficient economy.

Such a phenomenon is prominent in East Asia, for example. In this area, foreign direct investments flow mainly from Japan and China to other countries. Although the capital accumulation sufficiently advances and a limited 
number of capitalists and banks surprisingly become rich, the labor income of most residents including those in Japan and China stagnates. Income disparity is one of the most urgent problems in East Asia.

\section{The Optimum Currency Area as the Unification of Central Banks}

In the previous section, we showed that the non-cooperative actions of central banks have quite harmful effects on both countries. In this sense, we propose the unification of central banks. According to Mundell [1], a currency area is defined as follows:

"A single currency implies a single central bank (with note-issuing power) and therefore a potentially elastic supply of interregional means of payment." (p. 568)

We adopt this definition of a currency area.

When central banks are unified and a currency area is formed, the twin countries, A and B, can be treated as a single country, and hence, monetary coordination becomes possible. Because of the symmetry of the countries, the optimal coordination policy is also symmetric. Hence the two-step game extended in 2.3 requires equal allocation of real capital. Thus, we obtain $m^{A}=m^{B}=1$ and $\varepsilon^{A}=\varepsilon^{B}=0$. It is evident that the social welfare of each country (8) becomes $\theta \eta^{-1}$. This is the maximal value that each country attains. In this sense, these twin countries together constitute an optimum currency area ${ }^{2}$.

\section{Results and Analyses}

We reconsider the theory of optimum currency area from the perspective of resource allocation and income distribution. The obtained results are as follows.

We concentrate on the case of twin countries under perfect capital mobility and immobile labor forces. This assumption seems natural if we consider the significance of the existence of nation states.

When each central bank pursues its national interests, that is, the social welfare of its immobile labor force (i.e., the residents), dire economic consequences emerge. Each central bank is led to adopt an artificial high interest policy because more capital induced by a rate slightly higher than the rates of its rival central bank brings about higher incomes for the business skills possessed by the residents

\footnotetext{
${ }^{2}$ Hamada [4] and [5] also analyze not only how past monetary integrations were generated but also what policies were desirable to sustain such union, although his models are basically static and find difficulty in expressing functions of money explicitly.

${ }^{3}$ Casella [6] analyses the utility of monetary union as the saving of transaction costs. However, the substance of such costs is not necessarily clear. Although Basevi, Delbono, and Delnicolo [7] argue that there are microeconomic benefits from the monetary integration, they do not find the existence of the fierce zero-sum game between the central banks that we deal here. That is, both studies do not directly connect with the theoretical relationship between factor mobility and the necessity of a currency area that is the most serious concern of Mundell [1].
}

of that central bank's nation. However, such competitive and escalating interest-raising is devastating and cumulative, and it does not end until all the residents' income is absorbed by the real capital without nationality. Thus, a serious income disparity and a large decrease in social welfare occur. It is clear that the nation is not an optimum currency area.

When the two central banks are unified and the monetary coordination becomes possible, such catastrophic competition ceases. Real capital is allocated equally by abolishing the competitive and artificial high-interest policy. Just enough external money is supplied to ensure the full-employment equilibrium in each country. Thus, the social welfare achieves its maximum. In other words, our twin countries under perfect capital mobility constitute an optimum currency area. It is also noteworthy that our approach is based on a rigorous dynamic microeconomic foundation, and thus, enables the economic welfare analysis. In this sense, we succeed in updating and extending the theory of Mundell $[1]^{3}$.

\section{Concluding Remarks}

We obtain the result that twin-countries with perfect capital mobility should form a currency area in the sense of Mundell [1].

We must note some limitation of our work. The first is the difficulty of central bank unification. Bureaucrats who operate the unified central bank may be of different nationalities. Differences due to culture, ethnicity, tradition, and etc., are not as easy to overcome as our theory assumes. It takes more time than we expect to ensure fare policy coordination. As Hamada [5] argues, in general, any monetary integration cannot works well without accomplishing political integration beforehand, at least historically.

The second concerns the glut of foreign direct investment. In reality, the volume and range of mobile real capital is large and wide. It is feared that the world as a whole may become a unique optimum currency area. Nevertheless, it is certain that such a tremendous and enlarged organization would never work well. It may be more practical to place a levy on international capital movement, like the Tobin tax.

\section{REFERENCES}

[1] R. A. Mundell, "A Theory of Optimum Currency Areas," American Economic Review, Vol. 51, No. 4, 1961, pp. 657665.

[2] M. Otaki, "A Welfare Economics Foundation for the FullEmployment Policy," Economics Letters, Vol. 102, No. 1, 2009, pp. 1-3. doi:10.1016/j.econlet.2008.08.003

[3] A. Rubinstein, "Perfect Equilibrium in a Bargaining Model," Econometrica, Vol. 50, No. 1, 1982, pp. 97-110. doi: $10.2307 / 1912531$ 
[4] K. Hamada, "On the Political Economy of Monetary Integration," In: R. Z. Aliber, Ed., National Monetary Policies and the International Financial System, University of Chicago Press, Chicago, 1974.

[5] K. Hamada, "On the Coordination of Monetary Policies in a Monetary Union," Paper Presented at the Colloquium on New Economic Approach to the Study of International Integration, European University Institute, 1979.
[6] A. Cassella, "Participation in a Monetary Union," American Economic Review, Vol. 82, No. 4, 1992, pp. 847-863.

[7] G. Besevi, F. Delbono and V. Delnicolo, "International Monetary Cooperation and Economic Influence," Journal of International Economics, Vol. 28, 1990, pp. 1-23. 